\title{
Ley natural y ética discursiva La ley natural en Tomás de Aquino como gramática del discurso moral ${ }^{*}$
}

\author{
Natural Law and Discursive Ethics \\ Natural law in Thomas Aquinas as a grammar of moral discourse \\ Recibido: 15 de julio de 2009 - Revisado: 28 de julio de 2009 - Aceptado: 03 de septiembre de 2009
}

Luis Fernando Barzotto**

Traducción de Alfredo de J. Flores

\section{Resumen}

El presente artículo pretende mostrar que la ética tomista de la ley natural sea inteligible a un partidario de la ética discursiva de Apel y Habermas. Para ello, presenta la teoría de la ley natural de Tomás de Aquino como una gramática del discurso moral. La "traducción", según la terminología contemporánea de la ética tomista, pretende establecer un debate con los partidarios de la ética discursiva, adelantando en la tesis según la cual, en su función de controlar el sentido de las proposiciones que integran el discurso moral, la ética tomista es superior a la ética discursiva.

Palabras claves

Ley natural, ética, Tomás de Aquino, ética discursiva, argumentación moral.

\begin{abstract}
The present article is an attempt to make the Thomist ethics of the natural law intelligible to a supporter of Apel and Harbermas's discourse ethics. In order to do so, it presents Aquinas's theory of natural law as the moral discourse's grammar. This 'translation' of Thomist ethics into contemporary terminology aims at establishing a dialogue with those who uphold discourse ethics by advancing the thesis that, Thomist ethics is superior to discourse ethics in performing the function of controlling the sense of propositions that belong to the moral discourse.
\end{abstract}

Key words

Natural law, ethics, Thomas Aquinas, discoursive ethics, moral argumentation.

* Artículo de reflexión, resultado de Investigación.

** Doctor en Derecho. Universidad Sao Pablo. Profesor de Filosofía del Derecho. Universidad Federal do Río Grande.

Correo electrónico:

luis.barzotto@ufrgs.br 


\section{Preliminares}

El objetivo de este artículo es presentar los primeros principios de la teoría de la ley natural de Tomás de Aquino como una gramática del discurso moral. Esa gramática es constituida por una sintaxis del deber (el primer principio de la razón práctica), una semántica del bien (los tres bienes básicos) y una pragmática de la alteridad (la regla de oro). Esa gramática establece las condiciones de sentido de los argumentos morales. Proposiciones que no están en conformidad con los primeros principios carecen de sentido moral. Por sentido moral se entiende aquí la capacidad de un enunciado de expresar los conceptos fundamentales de la realidad moral: deber, bien y alteridad ${ }^{1}$.

Con ese modo de presentar la ley natural, se buscará iniciar un diálogo con las tendencias de la filosofía moral situadas en el denominado "paradigma lingüístico" de la filosofía. Esas tendencias recusan cualquier intento de fundamentar metafísicamente la moral, aceptando apenas el hecho del lenguaje como fundamento seguro de la reflexión ética. Ante ese escenario, cabe al tomista, fiel a la actitud de su maestro de buscar la verdad en la confrontación dialéctica con otras tradiciones, articular la doctrina de la ley natural en los términos que permitan el debate con propuestas éticas vinculadas al paradigma lingüístico, entre las cuales sobresale la denominada "ética discursiva".

En esa senda, iniciamos la exposición por una breve descripción de la ética discursiva, teoría ética vinculada a los nombres de los filósofos alemanes Jürgen Habermas y KarlOtto Apel, para, en la secuencia, mostrar de qué modo la doctrina de la ley natural puede ser traducida en términos comprensibles para la referida teoría y, al mismo tiempo, probar su superioridad como teoría del discurso moral.

\section{La ética discursiva}

Para la ética discursiva, el único modo plausible de fundamentar las normas morales es el consenso de los propios destinatarios de la norma, acuerdo obtenido a través del discurso, una argumentación práctica realizada en conformidad con un procedimiento.

El procedimiento que preside el discurso consiste en un conjunto de reglas que son argumentativamente irrefutables. Todo hablante que venga a violar una de las reglas del discurso entra en contradicción performativa, la "contradicción entre el contenido proposicional de la sentencia y lo que en ella se presupone"2. El ejemplo clásico es la sentencia "el gato está sobre el tapete, pero yo no creo en eso". El acto de habla es autocontradictorio porque la proposición que afirma la existencia de un estado de cosas presupone la creencia del hablante en la existencia del estado de cosas.

La contradicción performativa en el discurso moral se sucede, por ejemplo, cuando un participante del discurso profiere la siguiente frase: "Los participantes del discurso son desiguales en derechos". Ahora bien, lo presupuesto de todo discurso dirigido hacia la obtención de consenso es la igualdad en derechos de los participantes. Por eso, Apel formula la siguiente regla de argumentación: "Todos los participantes del discurso en principio son iguales". Esa regla es inherente a la práctica del discurso. El consenso sólo es buscado entre iguales $^{3}$. Entre desiguales, vale el poder o la autoridad. Por eso, el acto de habla que afirma la desigualdad de aquellos que son presupuestos como iguales es autocontradictorio.

De ese modo, se pretende haber encontrado un "fundamento último" para la moral: se explicita un conjunto de reglas que son inmanentes a todo discurso práctico y cuya negación lleva a la autocontradicción. De hecho, la exigencia de que todos los interlocutores, en la búsqueda del consenso, sigan de modo estricto todas esas reglas es asumidamente una idealización, pero esa idealización siempre está anticipada en todo discurso real. De esa manera, se encuentra un fundamento sobre el 
que se puede edificar la práctica de justificar consensualmente las proposiciones morales.

\section{Deber, ética discursiva y ley natural}

La ética discursiva busca ser sucesora de la ética deontológica de $\mathrm{Kant}^{4}$, en la medida en que se limita a fundamentar normas, es decir, deberes, que son afirmados como independientes de cualquier concepción sobre el bien. Su principio fundamental de justificación de normas es: "Toda norma válida debe satisfacer la condición de que puedan ser aceptadas, con libertad por parte de todos los afectados, las consecuencias y efectos colaterales que previsiblemente resulten de su cumplimiento generalizado, para la satisfacción de los intereses de cada uno"s.

La norma o deber producidos por el consenso establecen la conexión entre una acción y el "interés de cada uno" o el "interés de todos" ". El deber tiene, de ese modo, un carácter sintáctico, conectando acción e interés. El deber no es autorreferente, como en Kant, pero posee un norte teleológico, el interés. Se puede decir que la realización del interés de todos es el bien último buscado por la práctica del discurso.

Tomás de Aquino tiene mayor claridad en lo que respecta al concepto de deber. El deber en su doctrina tiene explícitamente la función sintáctica de conectar la acción a un bien. Para Tomás, "que algo deba ser hecho, eso proviene de la necesidad de algún fin" el agente, "tiene la razón de bien" primer principio de la razón práctica, "el bien debe ser hecho y buscado, y el mal, evitado", no puede ser negado en el contenido de un discurso práctico. Su negación es autocontradictoria, pues el propio acto de habla que busca negarlo pretende un bien, precisamente el de negar el primer principio de la razón práctica, que afirma que debemos buscar el bien. El acto de habla busca el bien de negar que se busque el bien. Para el Aquinate, el deber es la expresión de la necesidad racional de una conducta para la realización de un bien. De ese modo, la acción debida sólo es inteligible a partir del bien que es el fin de la acción.

El primer principio de la razón práctica funciona como la condición sintáctica de uso del término 'deber' en las proposiciones morales. Una proposición como "realizar $x$ es un deber porque fue establecido por consenso o por una autoridad" es una proposición que, al pretenderse completa, carece de sentido moral en la medida en que su formulación no indica el bien que constituye el fin de la acción debida.

\section{Bien, ética discursiva y ley natural}

Aunque Habermas rechaza una "ética de bienes" ${ }^{10}$, prefiriendo el término 'interés', que permitiría evitar la afirmación del estatuto objetivo del bien, a veces él mismo identifica el interés de todos con "las ideas básicas de la igualdad de trato y del bien común alrededor de las cuales giran todas las morales, también en las sociedades premodernas"11. Con lo que podemos afirmar que el "interés de todos", intento de subjetivar el bien común, no es mantenido de forma coherente por Habermas, ni podría, una vez que el interés de todos no es el resultado del discurso, sino un bien presupuesto por él. De todas formas, la tesis de Habermas es la de que el deber es el concepto primario y el bien el concepto secundario de la ética.

El tomismo, por otro lado, afirma el carácter primario del bien con relación al deber, e igualmente su carácter objetivo, por oposición al interés. Por esa razón, se constituye como una "ética de bienes", bienes esos que por su condición de irrefutables en el interior del discurso pueden pretender objetividad y universalidad. Para el tomismo, el concepto de bien no es un concepto vacío a ser rellenado por el consenso o por el interés, sino que posee un contenido mínimo que controla semánticamente las afirmaciones sobre el bien.

La ley natural tomista identifica tres bienes como referentes necesarios del concepto 
de bien: la vida, la verdad y la comunidad ${ }^{12}$. La negación argumentativa del carácter de bienes de esos tres "básicos" implica autocontradicción"

Iniciemos por el bien vida. Hagamos las siguientes observaciones absolutamente triviales. Todo aquel que ingresa en un discurso sólo lo hace porque está vivo. Igualmente, se puede decir que el discurso es el medio de resolución de conflictos adoptado por aquellos que no quieren recurrir al uso de la violencia, un medio que pondría su vida en riesgo. Por fin, el discurso tiene como objetivo garantizar el "interés de todos", lo que presupone que los participantes desean mantenerse vivos para lograr provecho de los resultados del discurso, de donde la vida queda asumida como condición necesaria para todo y cualquier interés. O sea, la práctica del discurso presupone la vida como un bien, y por lo tanto ella no puede ser negada universalmente como bien. De ese modo, el acto de habla "la vida no es un bien" fracasa en su pretensión de inteligibilidad en el interior del discurso, una vez que instala una contradicción performativa entre la negación de la vida como un bien y la presuposición de que la vida es un bien.

El segundo bien que no puede ser negado en el interior del discurso es la verdad. "La verdad no es un bien" es una sentencia cuya autocontradicción no necesita mayores comentarios. Todo acto de habla asertórico posee una pretensión de verdad, de donde la verdad es el bien o el fin presupuesto por el enunciado asertórico. De ese modo, tener una pretensión implícita de decir la verdad es asumirla como un bien, o sea, como fin del acto de habla; simultáneamente, negarla explícitamente como bien es entrar en contradicción.

Por fin, el tercer y último bien básico que el tomista establece como contenido de todo uso discursivo del concepto de bien es la comunidad. Todo discurso moral es un emprendimiento de crear comunidad, que a su vez visa la manutención de la comunidad, pues tiene como fin la producción de normas que permitan la convivencia adecuada de todos los participantes. La comunidad es el bien presupuesto por todo participante del discurso. De ese modo, la proposición "la comunidad no es un bien", afirmada en el interior del discurso, que es a su vez una actividad que crea comunidad y que visa a la comunidad, es autocontradictoria.

De esa forma, es posible afirmar que una proposición como "el contenido del bien es determinado por el consenso" (o por una cultura o por una decisión política) es semánticamente incorrecta. Hay bienes que el discurso debe asumir como objetivos, es decir, independientes del discurso sobre el bien, y esos son los bienes básicos: vida, verdad y comunidad. Los tres bienes básicos funcionan como condiciones semánticas de sentido para todo uso del concepto de bien en las proposiciones morales.

\section{Alteridad, ética discursiva y ley natural}

La ética discursiva pretende ser una ética que toma la alteridad en serio. Según Habermas, los participantes del discurso no pueden dejar de considerar la perspectiva de los demás mientras evalúen cursos de acción y fundamentan normas: "Cada uno de nosotros tiene que poder ponerse en la situación de todos aquellos que resultarían afectados por la realización de una acción problemática o por la puesta en vigor de una norma controvertida"14. Eso porque el discurso, al involucrar al hablante en la búsqueda de una norma que lleve en cuenta el interés de todos, impone a cada uno la tarea de ponerse en la perspectiva de los demás. Entre tanto, para la ética discursiva, la perspectiva que incluye al otro sólo puede hacerse efectiva en el interior del discurso. Siguiendo aún en la visión de Habermas, la regla de oro $\mathrm{u}$ otro procedimiento monológico de universalización sigue relacionado a una visión egocéntrica de mundo. Solamente cuando la palabra viene efectivamente puesta a la disposición del otro es que se puede ampliar el propio horizonte para incluirlo ${ }^{15}$. 
Ahora bien, el tomismo se articula como ética de la alteridad precisamente por intermedio del mandamiento del amor o la regla de oro ${ }^{16}$. Para fines de diálogo con la ética discursiva vamos a quedarnos en la regla de oro en la formulación que le ha dado Santo Tomás: "Todo lo que queréis que os hagan los hombres, hacédselo vosotros a ellos"17. La regla de oro exige, en el campo de las relaciones interpersonales, que se asuma la equivalencia entre el 'yo' y el 'otro'. Esa equivalencia exige del 'yo' que él trascienda a la propia subjetividad para ponerse en la situación del 'otro'.

Hablando en los términos de pragmática de la comunicación, la regla de oro impone una determinada actitud a los usuarios del lenguaje en cambio de mensajes. La condición del mutuo entendimiento es precisamente ponerse en la perspectiva del otro. El orador busca ser entendido adecuando el mensaje a la perspectiva del oyente y este entiende el mensaje situándolo en el horizonte de la perspectiva del orador. Cada participante del discurso es llevado por la dinámica de la comunicación a ponerse en el lugar del otro. De ese modo, lejos de ser una proyección individualista, la regla de oro es la superación del egocentrismo. Sin la adopción de esta norma, no hay argumentación.

Pero la regla de oro no tiene solamente una función pragmática general, sino que también una función específicamente moral. Analicemos el acto de habla que niega la regla de oro en el interior de un discurso moral: "La regla de oro no es una regla válida para la argumentación moral". Con ese acto de habla, el orador pretende que aquello que vale moralmente para sí mismo no valga para los demás. Con eso, él se excluye del discurso moral, un discurso que presupone la universalidad. El enunciado que niega la regla de oro como regla moral es autocontradictorio: la equivalencia moral entre hablante y oyente, presupuesta por el acto de habla, es negada por el acto de habla. La regla de oro es moralmente irrefutable.
Como ejemplo de la utilización de la regla de oro en el campo del fundamento de los derechos humanos, podemos citar el caso del fundamento del derecho humano de asilo político, tal como es presentado en un texto de Ernst Tugendhat. Él inicia la exposición sobre ese tema afirmando que "el núcleo de la moral consiste (...) en la Regla de oro"18. Y que "con la ayuda de la Regla de oro podemos darnos cuenta con facilidad de que este derecho es, en realidad, un derecho fundamental (...). No necesitamos más que ponernos en el lugar de los refugiados políticos para reconocer de inmediato que, llegado el caso, no sólo querríamos ser admitidos, sino que contemplaríamos como un escarnio a nuestra propia dignidad humana el que se nos denegara la admisión solicitada" 19 .

No se puede afirmar argumentativamente un derecho humano para sí mismo y negarlo para los demás, porque toda proposición moral debe afirmar simultáneamente al hablante y al oyente como destinatarios de su contenido. Por tanto, el acto de habla que viole la regla de oro se excluye del campo moral, o sea carece de sentido moral, precisamente porque violó aquella que es la condición pragmática de sentido de toda proposición moral.

\section{Conclusión}

La moral, para la doctrina de la ley natural de Tomás de Aquino, no está fundada en el lenguaje, sino en la estructura ontológica de la persona humana. De ese modo, una etapa necesaria del debate con la ética discursiva sería demostrar que la gramática del discurso moral del tomismo posee su fundamento en la razón humana y en la naturaleza humana.

El tomista sabe que no puede haber sentido sin verdad, ni verdad sin el ser, y por eso él no separa metafísica y filosofía del lenguaje, esencia y gramática. Él sabe, como dice Wittgenstein, que "la esencia está expresada en la gramática"20. 


\section{Notas}

${ }^{1}$ La teoría de la ley natural de Tomás de Aquino esta considerada en el texto Una teoría sobre el discurso de fundamento de proposiciones morales. El discurso de aplicación de proposiciones morales es, en el tomismo, objeto de la teoría de la prudencia.

${ }^{2}$ Nedel. Ética e discurso, pág. 14.

${ }^{3}$ Apel ápud Nedel. Op. cit., pág. 47.

${ }^{4}$ Habermas ápud Nedel. Op. cit., pág. 37.

${ }^{5}$ Habermas ápud Apel, K. La ética del discurso como ética de la responsabilidad, pág. 178.

${ }^{6}$ Habermas. Aclaraciones, pág. 142.

${ }^{7}$ S.T. I-II, q. 99, a. 1.

${ }^{8}$ S.T. I-II, q. 94, a. 2.

${ }^{9}$ S.T. I-II, q. 94, a. 2; q. 99, a. 1.

${ }^{10}$ Habermas. Op. cit., págs. 187-190.

${ }^{11}$ Ibídem, pág. 162.

${ }^{12}$ S.T. I-II, q. 94, a. 2.

${ }^{13}$ Cf. Finnis, John. Ley natural y derechos naturales. Capítulo 3.

${ }^{14}$ Habermas. Op. cit., pág. 161.

${ }^{15}$ Ibídem, pág. 163.

${ }^{16}$ S.T. I-II, q. 94, a. 4; q. 99, a. 1.; q. 100, a. 3 ; q. 100, a. 11.

${ }^{17}$ S.T. I-II, q. 99, a. 1. 79.

${ }^{18}$ Tugendhat, Ernst. Ética y política, pág.
${ }^{19}$ Ibídem, pág. 75.

${ }^{20}$ Wittgenstein. Investigações filosóficas. $\S 371$.

\section{Referencias}

Apel, K.-O. (1998). "La ética del discurso como ética de la responsabilidad". En: Apel, K. Teoría de la verdad y ética del discurso. Barcelona: Paidós.

Aquino (De), T. (2000). Comentario a la Ética a Nicómaco de Aristóteles. Navarra: Eunsa.

Aquino (De), T. (2005). “Tratado da Lei”. En: Aquino. Suma Teológica. Vol. IV. São Paulo: Loyola.

Aquino (De), T. (2005). "Tratado da Justiça". En: Aquino. Suma Teológica. Vol. VI. São Paulo: Loyola.

Aristóteles. Ética a Nicómaco. Madrid. Centro de estudios constitucionales.

Finnis, J. (1998). Aquinas. Oxford: Oxford University Press.

Finnis, J. (2000). Ley natural y derechos naturales. Buenos Aires: Abeledo-Perrot.

Habermas, J. (1990). Pensamento pósmetafísico. Rio de Janeiro: Tempo Brasileiro.

Habermas, J. (1998). Facticidad y validez. Madrid: Trotta.

Habermas, J. (2000). Aclaraciones a la ética del discurso. Madrid: Trotta.

Habermas, J. (2000). Teoría de la acción comunicativa. 2 vols. Madrid: Taurus.

Kant, I. (1995). Fundamentação da metafísica dos costumes. Lisboa. Edições 70. 
Kant, I. (1999). Crítica da razão prática. Lisboa: Edições 70.

Nedel, J. (2006). Ética e discurso. São Leopoldo: Nova Harmonia.

Ricoeur, P. (2005). Caminos del reconocimiento. Madrid: Trotta.
Ricoeur, P. (2006). Sí mismo como otro. México: Siglo XXI.

Tugendhat, E. (1998). Ética y política. Madrid: Tecnos.

Wittgenstein, L. (1991). Investigações filosóficas. São Paulo: Nova Cultural. 
